\title{
Multicentric infantile myofibromatosis of the small bowel detected by video capsule endoscopy in a child
}

Infantile myofibromatosis (IMF) is a rare group of reactive lesions. Their clinical, radiological, and pathological features may be confused with those of malignancy. The lung and mediastinum are the most common site of IMF in all pediatric age groups [1 -4].

We present a case of a 9-year-old boy presenting with a history of recurrent abdominal pain and chronic diarrhea since the age of one. He was under the third percentile for weight $(16 \mathrm{~kg})$ and height $(106 \mathrm{~cm})$. Physical examination and laboratory findings were normal. Abdominal computed tomography (CT) showed a nodular lesion of the liver (segment IV), cholelithiasis, and nephrolithiasis. CT of the thorax showed a lesion measuring $3.9 \times 2.2 \times 2.6 \mathrm{~cm}$ in the inferior left lung with bronchial and pulmonary vein invasion and mediastinal lymph nodes.

The patient underwent upper endoscopy and a subepithelial lesion with a central depression was found in the greater curvature of the gastric body. Colonoscopy showed multiple subepithelial lesions with a central ulceration, some of them with fibrin, varying in size from $3 \mathrm{~mm}$ to $20 \mathrm{~mm}$ ( Fig. 1). Video capsule endoscopy (MiroCam; Intromedic, Seoul, Korea) showed two lesions in the jejunum similar to those found in the colon and stomach ( Fig. 2; Video 1). Endoscopic ultrasonography of the colon with $15-\mathrm{MHz}$ miniprobes showed a well-delimited, hypoechogenic, homogeneous, fusiform lesion with a central ulceration originating from the muscle layer, measuring $9.2 \times 13.2 \mathrm{~mm}(\bullet$ Fig. 3 ).

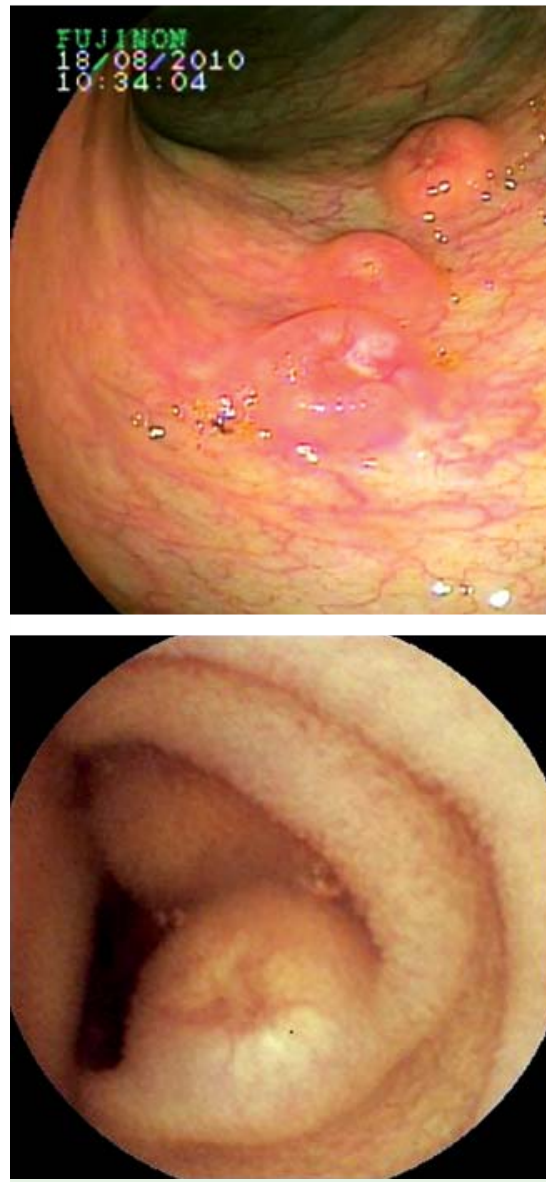

Fig. 2 Video capsule endoscopy showing two subepithelial lesions in the jejunum.

\section{Video 1}

Video capsule endoscopy shows small-bowel tumors in multicentric infantile myofibromatosis.

Biopsies were taken from the gastric and colonic lesions and a pathological diagnosis of IMF was made. The peripheral area showed spindle cells (myofibroblasts) with eosinophilic cytoplasm and ovoid nuclei, with less differentiated, rounder cells with pale cytoplasm and basophilic, small round nuclei in the central portion. No cellular anaplasia was present and there were few mitoses. The mesenchymal cells stained with vimentin and actin, but were uniformly negative with CD117, CD34, Ki-67, MIB-1, and S-100 antigen. Aerobic, anaerobic, and mycobacterial cultures obtained from the specimen were negative.
Fig. 1 Colonoscopic image of the subepithelial lesion.

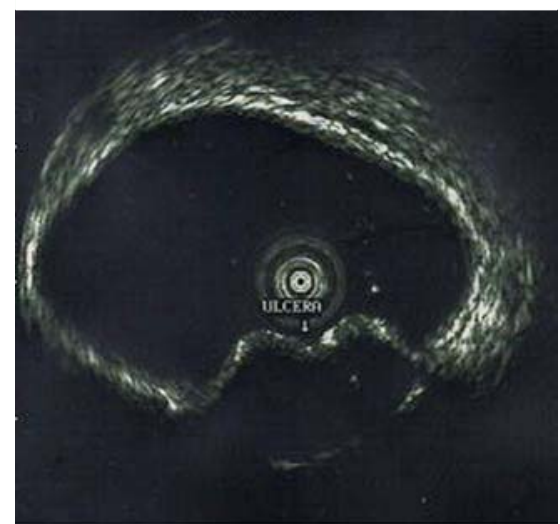

Fig. 3 Endoscopic ultrasonography of the colon with $15-\mathrm{MHz}$ miniprobes showing a welldelimited, hypoechogenic, homogeneous fusiform lesion with a central ulceration, originating from the muscle layer.

\section{Endoscopy_UCTN_Code_CCL_1AC_2AC}

Competing interests: None

\section{R. Alberti ${ }^{1}$, P. F. Souto Bittencourt ${ }^{2}$, \\ A. Rodrigues Ferreira ${ }^{2}$, \\ R. R. Rodrigues Da Silva², \\ S. Diniz Carvalho², \\ F. M. B. Nunes Cachicolo², M. Bahia², L. P. Fonseca de Castro ${ }^{2}$}

${ }^{1}$ Department of Surgery, Federal University of Minas Gerais, Santa Casa de Belo Horizonte, Belo Horizonte, Brazil

2 Department of Pediatrics, Federal University of Minas Gerais, Santa Casa de Belo Horizonte, Belo Horizonte, Brazil 


\section{References}

1 Lasso Betancor CE, Vázquez Rueda F, Vargas $\mathrm{Cruz} V$ et al. Congenital solitary infantile myofibroma: report of two cases. Cir Pediatr 2011; 24: 184-187

2 Smith $A$, Orchard D. Infantile myofibromatosis: two families supporting autosomal dominant inheritance. Australas J Dermatol 2011; 52: 214-217

3 Al-Jazaeri A, Al-Zahem A, Al-Maziad $\mathrm{H}$ et al. Unilateral breast mass in an infant: a rare presentation of spontaneously regressing myofibromatosis. J Pediatr Surg 2010; 45: $1896-1899$

4 Larralde M, Hoffner MV, Boggio P et al. Infantile myofibromatosis: report of nine patients. Pediatr Dermatol 2010; 27: 29-33
Bibliography

Dol http://dx.doi.org/

10.1055/s-0032-1309703

Endoscopy 2012; 44: E258-E259

(c) Georg Thieme Verlag KG

Stuttgart · New York

ISSN 0013-726X
Corresponding author

L. R. Alberti, MD, PhD

Rua Professor Baroni 151, apto 401

Belo Horizonte

MG 30440-180

Brazil

Fax: +55-31-32416668

luizronaldoa@yahoo.com.br 